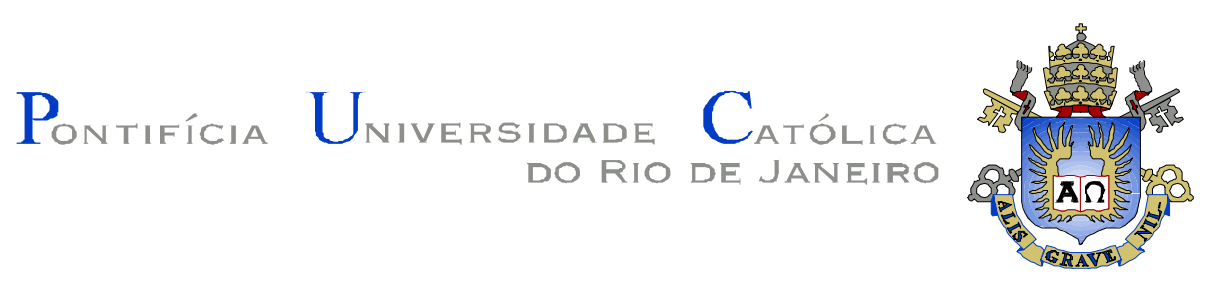

Flavia Di Luccio

\title{
Do lluminismo à Web Semântica \\ Reflexões sobre a comunicação com base em uma única língua
}

\section{Tese de Doutorado}

Tese apresentada como requisito parcial para obtenção do título de Doutor pelo Programa de PósGraduação em Psicologia da PUC-Rio.

Orientador: Ana Maria Nicolaci-da-Costa Co-orientador: Danilo Marcondes de Souza Filho 


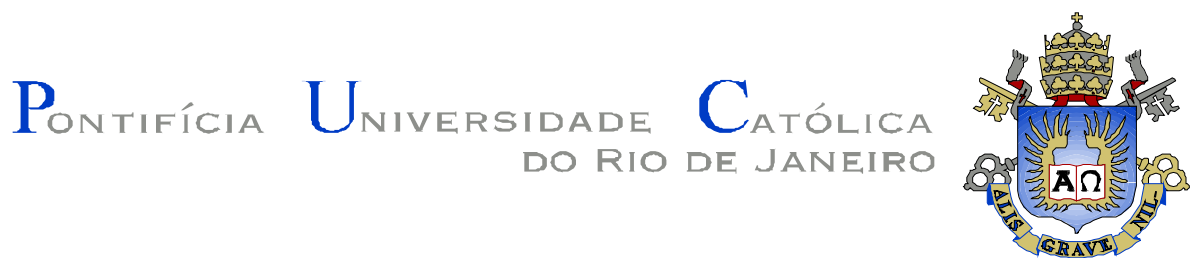

Flavia Di Luccio

\title{
Do lluminismo à Web Semântica
}

Reflexões sobre a comunicação com base em uma única língua

Tese apresentada como requisito parcial para obtenção do título de Doutor pelo Programa de Pós-Graduação em Psicologia da PUC-Rio. Aprovada pela Comissão Examinadora abaixo assinada.

\author{
Ana Maria Nicolaci-da-Costa \\ Orientador \\ Departamento de Psicologia - PUC-Rio \\ Danilo Marcondes de Souza Filho \\ Co-orientador \\ Departamento de Filosofia - PUC- Rio \\ Daniela Romão-Dias \\ Departamento de Psicologia - PUC-Rio
}

Violeta de San Tiago Dantas Barbosa Quental

Departamento de Letras - PUC-Rio

Rosane de Albuquerque dos Santos Abreu

UFRJ

Solange Coelho Vereza

Instituto de Letras - UFF

Paulo Fernando Carneiro de Andrade

Coordenador(a) Setorial do Centro de Teologia e Ciências Humanas -

PUC-Rio

Rio de Janeiro, 25 de fevereiro de 2010 
Todos os direitos reservados. É proibida a reprodução total ou parcial do trabalho sem autorização da universidade, da autora e do orientador.

Flavia Di Luccio

Graduou-se em Letras (português/inglês) pela Universidade Santa Úrsula em 1999 e se especializou em Língua Inglesa (2002) e em Português para Estrangeiros (2003) pela PUC-Rio. Obteve o título de Mestre em Psicologia pela PUC-Rio em 2005. Atualmente é pesquisadora do Núcleo de Estudos em Tecnologia e Subjetividade (NETS) no Departamento de Psicologia da PUC - Rio e atua principalmente nos seguintes temas: linguagem e tecnologia, redes sociais e Web Semântica.

Ficha Catalográfica

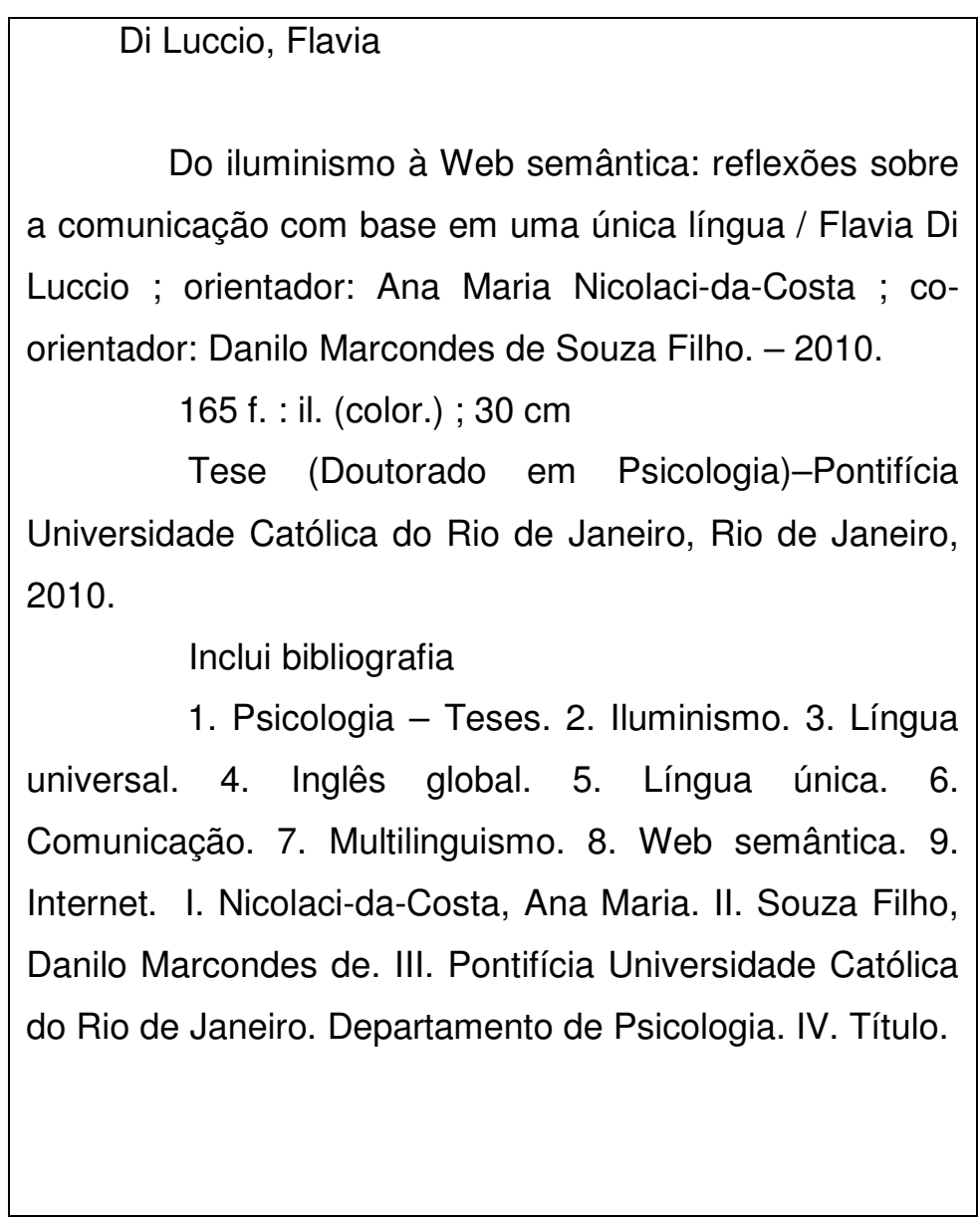

CDD: 150 


\section{Agradecimentos}

À Ana Maria Nicolaci-da-Costa, minha orientadora, por ter me acompanhado desde o mestrado. Obrigada pela confiança, orientação cuidadosa e por ter embarcado comigo nessa "aventura".

Ao Danilo Marcondes, meu co-orientador, por ter me apresentado o mundo de Kant e dos iluministas. Obrigada pelas leituras sugeridas e pelos ensinamentos.

À Violeta Quental, por ter me indicado o caminho da Web Semântica e pelas preciosas dicas de leituras.

À Carmelita, pela participação sempre importante na minha vida acadêmica.

Aos meus pais Carlos e Vera, por torcerem por mim sempre.

Ao meu marido Claudio, por todo apoio e paciência. Obrigada por estar sempre ao meu lado.

Ao meu irmão Marco, pelas dicas sobre o mundo acadêmico.

Ao NETS, pelas sugestões e incentivo. Obrigada Rosane, Dani, Betty, Mariana e Roberta.

Aos professores da pós-graduação do Departamento de Psicologia, por tudo que me ensinaram.

À Monique Augras pelas ricas discussões no início do doutorado.

À Marcelina e Verinha, pela atenção e ajuda.

Aos meus colegas de turma pelas discussões e trocas no início do doutorado.

A amiga Ana Jensen, pela revisão cuidadosa, ótima tradução e apoio constante. 
Ao amigo Steve, pelas palavras amigas e bem humoradas.

Aos amigos Sérgio, Andréa e Érika, pelas amizades verdadeiras.

Aos meus alunos, pela torcida.

A todos meus amigos que me incentivaram ao longo desta jornada.

À VRAc-PUC-Rio e à FAPERJ, pelo apoio financeiro.

A Deus, por ter estado sempre ao meu lado ao longo deste trabalho. 


\section{Resumo}

Di Luccio, Flavia; Nicolaci-da-Costa, Ana Maria; Souza Filho, Danilo Marcondes de. Do Iluminismo à Web Semântica: reflexões sobre a comunicação com base em uma única língua. Rio de Janeiro, 2009. 165p. Tese de Doutorado - Departamento de Psicologia, Pontifícia Universidade Católica do Rio de Janeiro.

Discussões a respeito da comunicação entre os homens e da diversidade linguística perpassam a história. É possível afirmar que Platão (427 - 347 a.C) e Aristóteles (384 - 322 a.C) instigaram filósofos e linguistas a buscar incessantemente explicações para a variedade de línguas existentes no mundo, bem como a investigar suas origens e características em comum. A obsessão por encontrar a língua que teria dado origem a todas as outras línguas não cessou, como também não cessou o desejo de retorno a esta primeira língua. Este desejo faz com que filósofos e linguistas há muito venham sustentando a criação e utilização de uma língua única. Esta possibilitaria a comunicação universal entre os homens independentemente de onde estes tivessem nascido, da cultura a que pertencessem ou da língua materna que falassem. Em outras palavras, poderia haver uma comunicação livre e democrática. Consequentemente, o acesso aos saberes também seria livre, o que daria lugar à concretização de uma das ambições do projeto iluminista: o esclarecimento do homem a partir da sua própria capacidade de conhecer o real de forma autônoma.

Tomando como ponto de partida essas questões, foi realizado um estudo histórico que teve como objetivo principal investigar os caminhos que a busca de uma língua única de comunicação vem seguindo desde o Iluminismo até a contemporaneidade, principalmente após o advento da Internet. Para tal, esta investigação tem início com a concepção de Kant sobre o Iluminismo, seguida das ideias de dois de seus contemporâneos, Condorcet e Condillac, escolhidos por sugerirem o uso de uma língua universal como alternativa para o esclarecimento humano. $\mathrm{O}$ estudo prossegue com uma breve descrição dos projetos de língua universal dos séculos XIX e início do século XX e apresenta as razões para os seus fracassos; passa posteriormente pela segunda metade do século XX e pela tentativa de se fazer da língua inglesa a língua única de comunicação no mundo; finalmente, chega à Revolução Digital. Nesta última fase, o debate concernente à 
comunicação livre, independentemente da língua, e ao acesso irrestrito ao conhecimento se veem reforçados com o aparecimento da terceira geração da Internet, a chamada Web Semântica, que tem reavivado os ideais dos projetos iluministas e mostrado ser um caminho possível para a comunicação universal e o esclarecimento humano.

\section{Palavras-chave}

Iluminismo, língua universal, inglês global, língua única, comunicação, multilinguismo, Internet, Web 2.0, Web Semântica. 


\section{Abstract}

Di Luccio, Flavia; Nicolaci-da-Costa, Ana Maria; Souza Filho, Danilo Marcondes de. From Enlightenment to Semantic Web: reflections about communication based on a single language. Rio de Janeiro, 2009. 165p. Tese de Doutorado - Departamento de Psicologia, Pontifícia Universidade Católica do Rio de Janeiro.

Since the beginning of times there have been discussions about linguistic diversity and the communication among men. One can easily say that Plato (427 347 b.c) and Aristotle (384 - 322 b.c) led both linguists and philosophers to constantly search for explanations concerning the origins and common characteristics of the many languages that exist in the world. It seems that the obsession to find the one language from which all others are supposed to derive still persists, as does the desire to return to it. This is the reason why philosophers and linguists fundamentally support the development and use of a single language. Such a language would make possible the communication among men on a universal level, irrespective of their birth place, culture or mother tongue. In other words, a free and democratic communication could take place and there would also be free access to knowledge. One of the Enlightenment's ambitions could therefore be achieved: men would be able to perceive reality autonomously.

Taking those issues as a starting point, a historical study was developed to investigate the search for a single language, from the Enlightenment until contemporary times, particularly after the advent of Internet. For this purpose, this study begins with Kant's conception of Enlightenment, followed by the ideas of two of his contemporaries, Condorcet and Condillac, who suggested the use of a universal language as a means for man to reach Enlightenment. The study discusses universal language projects of the $19^{\text {th }}$ and early $20^{\text {th }}$ centuries and points out the reasons for their failures. It proceeds with a presentation of the attempt to make English the worldwide language of communication from the second half of the $20^{\text {th }}$ century until the Digital Revolution. It argues that, at this stage, what matters is no longer the development of a single language, but of a free way of communicating, regardless of the language spoken and with unlimited access to knowledge. This is more clearly seen with the onset of the third generation of the Internet, known as the Semantic Web, which is recuperating the 
ideals of the Enlightenment and has been proving to be a possible way for communication on a universal level and for man's Enlightenment.

\section{Key-words}

Enlightenment, universal language, global English, single language, communication, multilinguism, Internet, Web 2.0, Semantic Web. 


\section{Sumário}

1. Introdução 15

2. O Século das Luzes 20

2.1. O lluminismo de Kant 24

2.2. A língua universal de Condorcet 27

2.3. A arte do raciocínio restrita a uma língua universal 30

2.4. A busca por uma língua universal nos séculos XIX e XX 36

2.5. Os fracassos dos projetos 38

3. A língua inglesa e seu papel a partir da segunda metade do 41 século XX

3.1. A língua global de David Crystal 42

3.1.1. Quando uma língua se torna global 43

3.1.2. A língua inglesa estava no lugar certo e na hora certa 45

3.1.3. Possíveis atitudes em relação a uma língua global 50

3.1.3.1 Língua global: um perigo? 51

3.1.4. Para onde a língua global da contemporaneidade está 55 caminhando?

3.1.5. O projeto de Crystal 58

3.2. A língua franca de Seidlhofer 61

3.2.1. O ensino do English as a Lingua Franca para não-nativos 63 como alternativa de comunicação universal eficaz 
3.2.2. O projeto de English as a Lingua Franca de Seidlhofer

3.2.2.1. Uma real possibilidade do inglês como língua franca? 67

3.3. O World English de Rajagopalan 70

3.3.1. Os motivos que levaram ao surgimento do World English 72

3.3.2. A rejeição declarada, a aceitação resignada, o esperanto e o 73 multilinguismo

3.3.3. O World English e a atitude realista como ideal 75

3.4. A incessante busca pela língua única de comunicação 77

4. A comunicação na Rede $\quad 78$

4.1. O uso da língua inglesa na Rede e a comunicação on-line na 79 visão de Crystal

4.1.1. Um novo tipo de comunicação 83

4.1.1.1. Uma nova linguagem para um novo tipo de comunicação 84

4.1.1.2. O caráter multilíngue da Rede 90

4.2. A tradução automática e sua contribuição ao caráter 93

multilíngue da Rede

4.3. O multilinguismo já concretizado

97

4.3.1. Algumas dúvidas que permanecem quanto ao papel da língua inglesa na Rede

4.3.2. As influências do netspeak em outras línguas 100

4.4. A comunicação on-line independentemente da língua 103

5. A Web dos significados 104

5.1. O primeiro momento da Rede 104

$\begin{array}{lr}\text { 5.2. A Web } 2.0 & 107\end{array}$ 
5.2.1. O início da Web colaborativa 108

5.2.2. A Web das wikis 114

5.2.3. As Redes Sociais 121

$\begin{array}{ll}\text { 5.2.3.1. Sites de compartilhamento } & 128\end{array}$

5.3. Web 3.0: o presente 131

5.3.1. Uma proposta repleta de desafios 133

5.3.1.1. A Web Semântica na prática 135

5.3.1.2. A Web das ontologias sob a ótica de Wittgenstein 138

5.3.1.3. A concretização da Web 3.0

6. Retorno aos projetos iluministas 152

7. Referências Bibliográficas 159 
“...notoriamente no hay clasificación del universo que no sea arbitraria y conjetural. La razón es muy simple: no sabemos qué cosa es el universo. 'El mundo - escribe David Hume - es tal vez el bosquejo rudimentario de algún dios infantil, que lo abandonó a medio hacer, avergonzado de su ejecución deficiente; es obra de un dios subalterno, de quien los dioses superiores se burlan; es la confusa producción de una divinidad decrépita y jubilada, que ya se ha muerto.'... Cabe ir más lejos; cabe sospechar que no hay universo en el sentido orgánico, unificador, que tiene esa ambiciosa palabra. Si lo hay, falta conjeturar su propósito; falta conjeturar las palabras, las definiciones, las etimologías, las sinonimias, del secreto diccionario de Dios."

Jorge Luis Borges, El idioma analítico de John Wilkins 